\title{
Video tracking in the extreme: Video analysis for nocturnal underwater animal movement
}

\author{
B. W. Patullo, G. Jolley-Rogers, and D. L. Macmillan \\ University of Melbourne, Parkville, Victoria, Australia
}

\begin{abstract}
Computer analysis of video footage is one option for recording locomotor behavior for a range of neurophysiological and behavioral studies. This technique is reasonably well established and accepted, but its use for some behavioral analyses remains a challenge. For example, filming through water can lead to reflection, and filming nocturnal activity can reduce resolution and clarity of filmed images. The aim of this study was to develop a noninvasive method for recording nocturnal activity in aquatic decapods and test the accuracy of analysis by video tracking software. We selected crayfish, Cherax destructor, because they are often active at night, they live underwater, and data on their locomotion is important for answering biological and physiological questions such as how they explore and navigate. We constructed recording arenas and filmed animals in infrared light. We then compared human observer data and software-acquired values. In this article, we outline important apparatus and software issues to obtain reliable computer tracking.
\end{abstract}

Changes in animal movement are of interest to a diverse range of scientific disciplines including neurobiology and the behavioral sciences. The assessment of movement is important not only for the insight it can provide into how animals function, but also because it can indicate changes in internal state that may only be detected by invasive techniques. It is therefore critical to select appropriate behaviors to monitor, and to have a reliable method of recording.

Motion tracking can be an efficient way to monitor animal movement (Kruk, 1997; Sussman, 1998). This involves recording the position of part of an animal through time. There have been significant advances from the early methods that used overlay boards (e.g., Rasnow, Assad, Hartmann, \& Bower, 1997; for a summary of these and others, see Noldus, Spink, \& Tegelenbosch, 2001; Reynolds \& Riley, 2002). One approach is to globally fit a surface to the object and track movement from landmarks, reflectors, or light-emitting diodes (referred to as "modeling"; see, e.g., MacIver \& Nelson, 2000). A simpler approach is to film the experiment and use computer tracking software to record movement. A range of commercially available software has been used, and some researchers have even written programs specific to their needs (e.g., commercial: Neuro Inspector, Božič, Skvarč, \& Abramson, 2004; Vidamex-V, Valentinčič, Kralj, Stenovec, Koce, \& Caprio, 2000; EthoVision, Sams-Dodd, 1995; self-programmed: Wu, Chan, Lam, Poon, \& Poon, 2000; Zurn, Jiang, \& Motai, 2005).

Motion-analysis software has proven useful in behavioral experiments. For procedures that require an observa- tion period, analysis can quickly become a substantial part of the project. Any reduction in this time is advantageous. Researchers have used software to track both invertebrate and vertebrate species (e.g., rats, Sams-Dodd, 1995; catfish, Valentinčič et al., 2000; voles, Dobly, 2001; beetles, Szentesi, Weber, \& Jermy, 2002; Noldus, Spink, \& Tegelenbosch, 2002; bees, Božič et al., 2004; snails and slugs, Schüder, Port, \& Bennison, 2004). Some also note that tracking was not always successful and required manual oversight (e.g., Sams-Dodd, 1995; for a discussion, see Sussman, 1998).

Two circumstances, low light and water, present particular difficulties and invite further refinement of methodology to improve the value of motion analysis. Aquatic arenas present a challenge, because water ripples from animal movement and reflection off the surface interferes with tracking (personal observation and inferred by methods in Keller, Powell, \& Weissburg, 2003; Panksepp \& Huber, 2004). Some researchers have devised creative solutions to these problems. For example, lobsters and crabs were fitted with a backpack with a battery and glowing light-emitting diodes (Horner, Weissburg, \& Derby, 2004; Keller et al., 2003), and crayfish were filmed with extra illumination from beneath an experimental arena and diffused light from above (Panksepp \& Huber, 2004). In these examples, there is an element of experimental invasion; a backpack, or being illuminated from beneath, would seldom, if ever, occur in the wild. Nocturnal activity or movement in the dark also makes motion analysis difficult because there is minimal or no visible light. Some studies

B.W.Patullo, b.patullo@zoology.unimelb.edu.au 
have managed to accomplish this. Zurn and colleagues (2005) tracked rats in darkness using near-infrared lightemitting diodes arranged in strips above the test arena, and Belmain and colleagues (2000) divided arenas into lit and dark zones.

Low-light underwater environments are relevant to crayfish. Many species are active at night (Procambarus clarkii, Page \& Larimer, 1972; Orconectes virilis, Hazlett, Rittschof, \& Ameyawakumfi, 1979; Astacus astacus, Abrahamsson, 1983; Cherax destructor, Merrick, 1993; Austropotamobius pallipes, Barbaresi \& Gherardi, 2001). Tracking their locomotion is also relevant to a number of behavioral questions under active investigation. For example, researchers have focused on exploratory movement around walls, and how the antennae and underlying nervous system are involved (Basil \& Sandeman, 2000; McMahon, Patullo, \& Macmillan, 2005; Patullo \& Macmillan, 2006; Shuranova, Burmistrov, \& Abramson, 2005). Further information on the accuracy of techniques of motion tracking would thus assist analysis in crayfish and potentially other species that monitor similar behavior (e.g., cockroaches, Camhi \& Johnson, 1999; ants, Dussutour, Deneubourg, \& Fourcassié, 2005).

Here, we tested the efficiency and accuracy of motiontracking software for analyzing crayfish movement. Cherax destructor were filmed in aquaria illuminated by infrared light. Measurements were recorded by two methods, computer software and human observer. We compared the two data sets to determine any differences between the two techniques.

\section{METHOD}

\section{Apparatus}

Tanks ( $45 \mathrm{~cm}$ long $\times 15 \mathrm{~cm}$ wide $\times 15 \mathrm{~cm}$ high) were constructed from 6-mm-thick black acrylic. The inner surfaces were sanded, to remove the original shine and provide traction for the crayfish when they walked. White dots of correction fluid ( 2-mm diameter, Pentel) were placed on the bottom to define two zones at either end of the tank (Figure 1). Two tanks were positioned on the floor of the husbandry room on foam.

A black-and-white CCD camera (Jaycar, Victoria) with six builtin near-infrared light-emitting diodes was mounted on a tripod above the tanks, directly over the long walls (Figure 1A). Some reflection was unavoidable, but this method confined it to the edges rather than over the main observation area (Figure 1B). The camera placement also minimized parallax error. Two additional light sources, of the same brand as the cameras, were rigged above each short end of the tank (Figure 1A). They were positioned above walls and angled so as not to point directly perpendicular to the tank bottom, to minimize reflection. Other methods have been used to minimize reflection (e.g., Becco, Vandewalle, Delcourt, \& Poncin, 2006; Jadot, Donnay, Ylieff, \& Poncin, 2005) but this setup was the most appropriate for C. destructor. The technique is shown from the snapshot of a frame of footage in Figure 1B. The arenas were previewed on a monitor and recorded to VHS tape on a Panasonic video recorder (Figure 1A).

\section{Software Tracking}

Camera footage was digitized to MPEG-1 movies by connecting the videocassette recorder to a computer video card (PCTV Vision software, Pinnacle). Contrast and brightness were adjusted at the time of digitization because this was not possible from prerecorded movies within the software package. Movies were analyzed on EthoVision software (Version 3, Noldus Information Technologies) at the
A
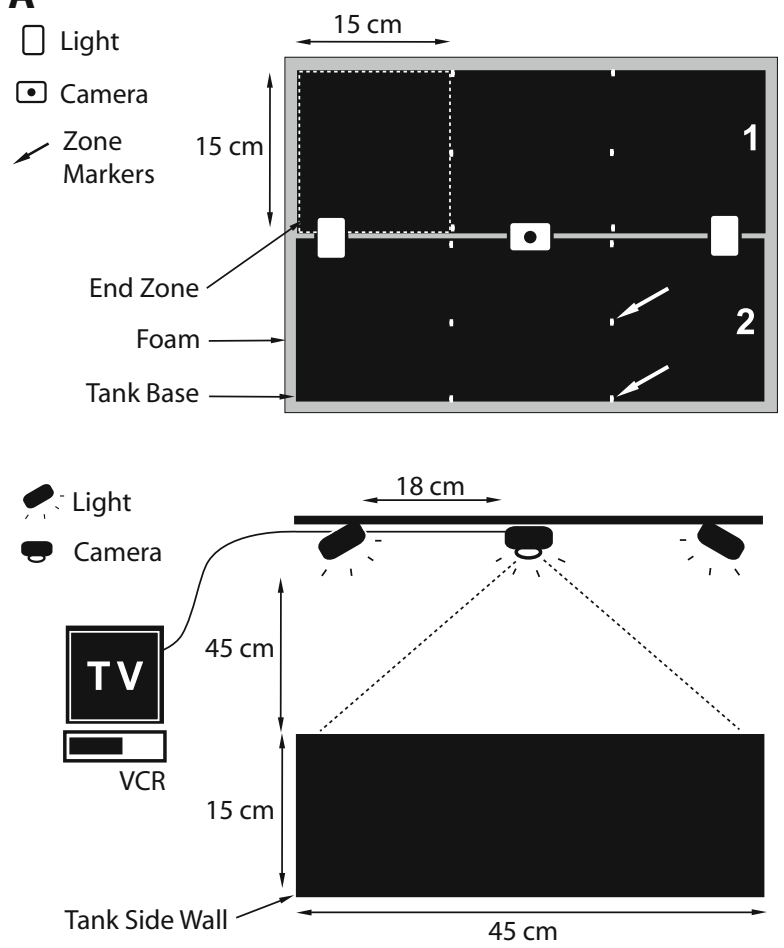

\section{B}
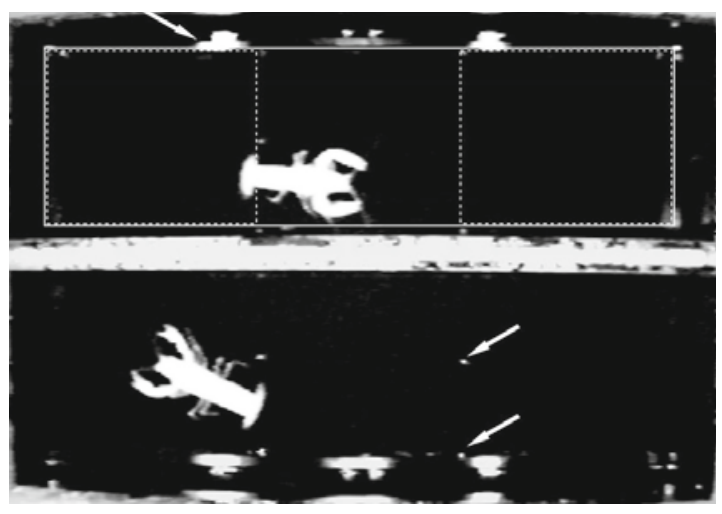

Figure 1. (A) Plan and side views of the setup of arenas and filming apparatus. Two tanks are shown (1 and 2). A CCD camera and infrared light sources were suspended above the center of the tanks by a tripod (not shown). White dots as markers (at white arrows, Tank 2) defined two end zones (left zone outlined by dotted box, Tank 1). A monitor (TV) and videocassette recorder (VCR) viewed and stored the footage. (B) Film image snapshot of the setup prior to software analysis. Crayfish bodies were of high contrast on the black background. The analysis areas are shown with solid and dotted rectangles. The arena area (solid rectangle) was defined, to eliminate reflection (white arrow, top tank). The end zones were defined by the zone markers (white arrows, bottom tank).

Integrative Neurosciences Facility (Howard Florey Institute, University of Melbourne). We briefly mention the software setup because other programs are likely to have equivalent settings that could be manipulated in a similar manner.

Preliminary observations and previous literature (e.g., SamsDodd, 1995) suggest that analysis software can mistakenly track 
points in the arena other than the moving animal. In preliminary trials, the differences between the observer and the software were marked, up to $200 \%$, in extreme instances (unpublished observations). After these trials, we repeatedly adjusted software settings for one trial until we had the optimal settings for our videos. This set the levels for the subsequent experiment, and generally, no further adjustments were necessary. Several key adjustments were made, and more detail on each is provided in the EthoVision help menus.

Reference image. The program uses a reference detection image to set starting levels for movement. This was defined from one of the first frames of each trial video clip when no animal was present. This was unlikely to vary greatly between trials, because the setup was the same between trials.

Detection threshold. This determines the sensitivity of what the software deems to be a change in the arena. Here, the user distinguishes between noise and actual movement of the animal. A lower and upper threshold can be set.

Tracking area. The program requires an area on the video to be defined, in which movement will be tracked. We outlined this area to include only the base, and not the walls (Figure 1B). This meant that movement of reflection at the surface, which was predominantly near the walls, with our apparatus, was not mistaken as a crayfish moving.

Filtering. Dithering and dilation were applied at the start and were adjusted periodically between trials. Dithering smooths the video signal to compensate for lost information that occurs when the analog signal is digitized into a movie file. Dilation is used to adjust the edge of the tracked area.

Contrast. High contrast and low brightness were set to produce a white crayfish on the black background. This maximized the contrast of the image. There are reports of tracking success with poorer contrasting images in other species (e.g., Zurn et al., 2005), but our unpublished observations on white backgrounds and in less infrared light suggest that this is more difficult for crayfish in these arenas.

Size of tracked object. The minimum size of the object tracked was always set above 20 pixels, because crayfish were always bigger than this, and it prevented tracking small changes in background movement of reflection or static.

Sampling rate. A low rate of 5 points/sec was selected. This provided sufficient detail to obtain the necessary movement data, and reduced the likelihood of missed points. The software tracked animals up to 5 times real time, which meant that settings could be altered and animals retracked if many points were mistracked.

\section{Manual Observations and Analysis}

A manual comparison of the tracking was made by a human observer. Footage was played in real time through the computer digitizer program. When the crayfish rostrum (most anterior point on the crayfish body, $\sim 3 \times 3$ pixels) entered and exited zones, time was recorded from the software's clock and entered into a spreadsheet. The rostrum was a clear point for the observer to follow, and has been used in other studies on C. destructor (e.g., McMahon et al., 2005). These data were summed for all entries into each zone, to produce the total time in each zone. The number of visits into each zone was also noted. These variables were selected on the basis of their importance to crayfish locomotor studies, ease of recording, and because they form the base of other measurements (e.g., average time, speed, first zone entered).

\section{Obtaining the Test Data}

Australian freshwater crayfish, Cherax destructor (Clark) were obtained from a commercial supplier. Body length, from the rostrum to the edge of the tail fan, was between 7 and $11 \mathrm{~cm}$. Animals were maintained in fiberglass aquaria $(120 \mathrm{~cm}$ long $\times 50 \mathrm{~cm}$ wide $\times 20 \mathrm{~cm}$ high) in a husbandry room on a reverse 12:12-h dark:light cycle at $18^{\circ} \mathrm{C} \pm 1^{\circ} \mathrm{C}$.

Recording took place during the dark period of the light cycle. A red light (15-W globe with red Ilford darkroom filter) assisted the observer to start trials. Human movement in this intensity of red light has minimal, if any, effect on C. destructor behavior (McMahon et al., 2005). The arenas were filled with tap water to a depth of $10 \mathrm{~cm}$. A temporary holding enclosure (upright $12-\mathrm{cm}$ diameter, $12-\mathrm{cm}$-high PVC tube) was placed in the center of each tank. Crayfish from the husbandry tanks were caught with a net and 1 was placed in each chamber for $2 \mathrm{~min}$. The red light was turned off and the enclosure was removed by hand to start the trial. After $10 \mathrm{~min}$, the crayfish were removed; this procedure was repeated for 10 animals.

\section{RESULTS AND DISCUSSION}

\section{Summary of Methodology}

There were a number of design and software features that were likely to have maximized the effectiveness with which crayfish were tracked in the dark. Once these settings were finalized, trials were generally tracked without any further adjustments. Four key steps were (1) using a reference image with no animals in the tank, (2) adjusting the detection threshold, (3) having a tracking area that eliminated ripple and reflection at the tank edges, and (4) using software filtering. Minor adjustments that may have assisted with tracking were (1) having a reasonable minimum size and sampling rate for the tracked image, (2) using a black background, (3) providing abundant infrared illumination not directly above the main recording area, (4) positioning the camera some distance above the tanks and not directly over the focal recording area, and (5) making sure the images had maximum contrast when the footage was digitized.

\section{Comparison of Techniques}

Of principal interest was whether the two modes of acquisition, software and human observer, differed, and whether either recording method altered the statistical outcome of behavioral measurements. We computed a two-factor ANOVA for method (software and observer) and zone (left and right end of the arena) in Systat (Version 11, Systat Software, Inc.). There was no difference in the results for either variable (number of visits and total time in an end area) when the methods and behavior were compared ( $p>.05$ for all tests, Table 1, Figure 2). Specifically, the method factor was not different between manual and computer tracking, and there was no difference in the exploration of the two end zones. There was also no significant interaction term, indicating that the method and

Table 1

\begin{tabular}{|c|c|c|c|c|}
\hline Source & $d f$ & Mean-Square & $F$ ratio & $P$ \\
\hline \multicolumn{5}{|l|}{ Number of Visits } \\
\hline Method & 1 & 5.625 & 0.938 & .339 \\
\hline Zone & 1 & 0.225 & 0.038 & .848 \\
\hline Method $\times$ zone & 1 & 1.225 & 0.204 & .654 \\
\hline Error & 36 & 5.997 & & \\
\hline \multicolumn{5}{|l|}{ Total Time in Zone } \\
\hline Method & 1 & 3.025 & 0.003 & .954 \\
\hline Zone & 1 & $1,677.025$ & 1.905 & .176 \\
\hline Method $\times$ zone & 1 & 87.025 & 0.099 & .755 \\
\hline Error & 36 & 880.242 & & \\
\hline
\end{tabular}

Note-Both the method (observer or software) and end zone (left or right) did not differ for the two variables measured (two-factor ANOVA, $p>.05$ for all comparisons) 

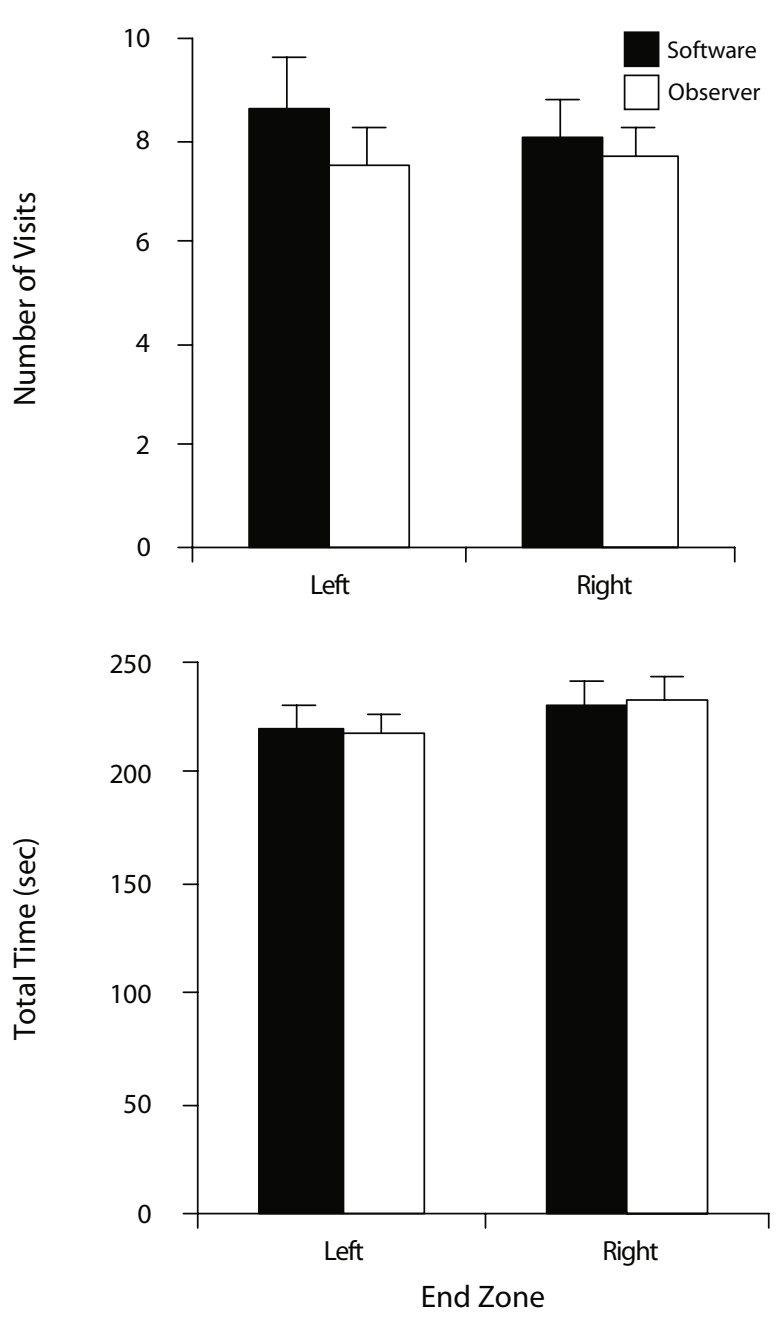

Figure 2. Graphs of the mean $(+S E M)$ number of visits to the two end zones (left and right) and mean $(+S E M)$ total time in those zones. Measurements from the EthoVision software are black bars and manual observer results are white bars. The two methods were not different $(p>.05$; see text).

zone use did not differ within the groups. Therefore, we conclude that the filming method produced data that did not differ between software- and observer-acquired values. Furthermore, if the data were used to test a behavioral hypothesis, there would have been no difference in the conclusions drawn.

\section{Assessment of the Tracking Techniques}

In some respects, the software was limited with respect to the biologically useful variables it could measure for crayfish in our arenas. Although it was capable of measuring over 20 variables, the most meaningful ones, for the purpose of crayfish tracking, were only those that describe locomotor behavior - for example, time, frequency of events, and speed. Some of these we recorded and verified with reasonable accuracy. Other software packages probably have those variables, and may therefore be more economically viable for recording crayfish movement if they have high tracking fidelity.
The ability to track the head rather than a varying point roughly in the center of the animal would also be advantageous. We could have detected a significant difference between observer and software just because the observer results were from the rostrum and EthoVision's were from the center of the animal. This was not the case, however, probably because the scale of our footage meant that this difference was small (approximately 15 pixels).

It took considerable time to digitize the video footage, because this had to be done in real time. Camera footage streamed to a computer, rather than to a video recorder, would eliminate this step. Care would still have to be taken to adjust the contrast for each recording. Also, analysis, such as the frequency and duration with which an animal swaps between forward and backward walking, were not possible without manual checking. Other techniques, such as diode arrays (e.g., Zurn et al., 2005), could do this, but they usually require specialist programming skill. Our design remains accessible to those without such knowledge.

Our method may have produced slightly different tracking to actual paths the crayfish walked, due to refraction. This was minimized by keeping the water shallow, and there was no discernible deformation of the crayfish on the footage. We interpret the results and their application, with this in mind, in the next section.

\section{Application of the Tracking Method}

Variables measured by the software could be used to describe crayfish locomotor movement in the arena. The mean ( $\pm S D, n=10$, software trial animals) total distance moved by crayfish was $934 \pm 215 \mathrm{~cm}$. The maximum distance moved without stopping was $5 \pm 3 \mathrm{~cm}$. The percentage of time in locomotor movement (forward or backward) was $31 \pm 13 \%$, equivalent to about $3 \mathrm{~min}$. Crayfish moved at a mean velocity of $1.5 \pm 0.3 \mathrm{~cm} / \mathrm{sec}$ throughout the 10-min observation time. Given that data collected by the observer and the software were not different, the accuracy of these variables is also high. This suggests that EthoVision could be used in behavioral studies for this type of data.

The technique could also be applied to monitor other species-for example, lobsters tracking odors (Horner et al., 2004) and fish swimming (e.g., Valentinčič et al., 2000). In several studies, researchers monitor additional variables besides the variables acquired by the software (Dobly, 2001; Sams-Dodd, 1995; Valentinčič et al., 2000). These studies, like ours, suggest that it is prudent to factor in some degree of human observation when using automated analysis, to confirm results or to record additional variables (Sussman, 1998). In our study, for example, had we wanted to measure the time spent walking backward, we would have had to manually record those times and relate them to the software-acquired measurements.

Software programming for more complex movements would be useful in a range of crayfish and other decapod behaviors (e.g., curve walking, Domenici, Jamon, \& Clarac, 1998; snapping behavior, Schmitz \& Herberholz, 1998; abdominal movement, Arnott, Neil, \& Ansell, 1998; Finley \& Macmillan, 2002; defense response, Copp \& Jamon, 2001; escape behavior in predator-prey interac- 
tions, Herberholz, Sen, \& Edwards, 2004). These more complex tasks may be able to be automated for motion analysis to improve the use of motion analysis for other biological questions.

The motion-analysis software provided a feasible, fast alternative to a human observer for the variables recorded, if the apparatus and software settings were fine-tuned. The method of tracking described in this study is likely to be advantageous to a range of other movement situations in which locomotor data are required. The noninvasive technique more closely reflects wild situations than do some other video methods, and can also be applied by inexperienced researchers with no programming knowledge. Some of the considerations we list are likely to be valid, particularly if behavior needs to be monitored in day and night periods. Motion analysis will continue to be a useful technique to biologists, but some degree of human observation may be needed to monitor a full range of behaviors.

\section{AUTHOR NOTE}

This research was supported by the Australian Research Council, with funding to D.L.M. We sincerely thank the staff, Julie Anne Quinne, Keith Buxton, Brett Purcell, and Michael Cowen, from the Integrative Neuroscience Facility at the Howard Florey Institute, for the use of, and their assistance with, the EthoVision software. We thank Luke Finley, Adrian McMahon, Helena Baird, and Lisa Koch for their ideas and valuable input to discussions during the project. Correspondence concerning this article should be addressed to B. W. Patullo, Department of Zoology, University of Melbourne, Parkville, VIC, 3010 Australia (e-mail: b.patullo@zoology.unimelb.edu.au).

\section{REFERENCES}

Abrahamsson, S. (1983). Trappability, locomotion, and diel pattern of activity of the crayfish Astacus astacus and Pacifastacus leniusculus Dana. Freshwater Crayfish, 5, 239-253.

Arnott, S. A., NeIL, D. M., \& Ansell, A. D. (1998). Tail-flip mechanism and size-dependent kinematics of escape swimming in the brown shrimp Crangon crangon. Journal of Experimental Biology, 201, 1771-1784.

Barbaresi, S., \& Gherardi, F. (2001). Daily activity of the whiteclawed crayfish, Austopotamobius pallipes (Lereboullet): A comparison between field and laboratory studies. Journal of Natural History, 35, 1861-1871.

Basil, J., \& Sandeman, D. (2000). Crayfish (Cherax destructor) use tactile cues to detect and learn topographical changes in their environment. Ethology, 106, 247-259.

Becco, C., Vandewalle, N., Delcourt, J., \& Poncin, P. (2006). Experimental evidences of a structural and dynamical transition in fish school. Physica A, 367, 487-493.

Belmain, S. R., Simmonds, M. S. J., \& Blaney, W. M. (2000). Behavioral responses of adult deathwatch beetles, Xestobium rufovillosum de Geer (Coleoptera: Anobiidae), to light and dark. Journal of Insect Behaviour, 13, 15-26.

Božıč, J., SkvarČ, J., \& Abramson, C. I. (2004). Video analysis in bee biology using Neuro Inspector. Apiacata, 38, 366-374.

CAMHI, J. M., \& Johnson, E. N. (1999). High frequency steering maneuvers mediated by tactile cues: Antennal wall following in the cockroach. Journal of Experimental Biology, 202, 631-643.

CopP, N. H., \& JAMON, M. (2001). Kinematics of rotation in place during defense turning in the crayfish Procambarus clarkii. Journal of Experimental Biology, 204, 471-486.

Dobly, A. (2001). Movement patterns of male common voles (Microtus arvalis) in a network of Y junctions: Role of distant visual cues and scent marks. Canadian Journal of Zoology, 79, 2228-2238

Domenici, P., JAMON, M., \& ClaraC, F. (1998). Curve walking in freely moving crayfish (Procambarus clarkii). Journal of Experimental Biology, 201, 1315-1329.

Dussutour, A., Deneubourg, J., \& Fourcassié, V. (2005). Amplification of individual preferences in a social context: The case of wallfollowing in ants. Proceedings of the Royal Society B, 272, 705-714.

Finley, L., \& Macmillan, D. L. (2002). An analysis of field potentials during different tailflip behaviours in crayfish. Marine \& Freshwater Behaviour \& Physiology, 35, 221-233.

Hazlett, B., Rittschof, D., \& Ameyawakumfi, C. (1979). Variation in the caudal color spot of the crayfish Orconectes virilis (Hagen) (decapoda, cambaridae). Crustaceana, 36, 56-60.

Herberholz, J., Sen, M. M., \& EdWARds, D. H. (2004). Escape behavior and escape circuit activation in juvenile crayfish during prey-predator interactions. Journal of Experimental Biology, 201, 1855-1863.

Horner, A. J., Weissburg, M. J., \& Derby, C. D. (2004). Dual antennular chemosensory pathways can mediate orientation by Caribbean spiny lobsters in naturalistic flow conditions. Journal of Experimental Biology, 207, 3785-3796.

Jadot, C., Donnay, A., Ylieff, M., \& Poncin, P. (2005). Impact implantation of a transmitter on Sarpa salpa behaviour: Study with a computerized video tracking system. Journal of Fish Biology, 67, 589-595.

Keller, T. A., Powell, I., \& Weissburg, M. J. (2003). Role of olfactory appendages in chemically mediated orientation of blue crabs. Marine Ecology Progress Series, 261, 217-231.

KRUK, M. R. (1997). Measuring behaviour into the twenty-first century. Trends in Neurosciences, 20, 187-189.

MacIver, M. A., \& NeLson, M. E. (2000). Body modeling and modelbased tracking for neuroethology. Journal of Neuroscience Methods, 95, 133-143.

McMahon, A., Patullo, B. W., \& Macmillan, D. L. (2005). Exploration in a T-maze: The crayfish Cherax destructor suggests bilateral comparison of antennal tactile information. Biological Bulletin, 208, 183-188.

MerRicK, J. R. (1993). Freshwater crayfish of New South Wales. Marrickville, New South Wales: Southwood Press.

Noldus, L. P. J. J., Spink, A. J., \& Tegelenbosch, R. A. J. (2001). EthoVision: A versatile video tracking system for automation of behavioural experiments. Behavior Research Methods, Instruments, \& Computers, 33, 398-414.

Noldus, L. P. J. J., SpinK, A. J., \& Tegelenbosch, R. A. J. (2002). Computerised video tracking, movement analysis and behaviour recognition in insects. Computers \& Electronics in Agriculture, 35, 201-227.

PAGE, T., \& LARIMER, J. L. (1972). Entrainment of the circadian locomotor activity rhythm in crayfish: The role of the eyes and caudal photoreceptor. Journal of Comparative Physiology, 78, 107-120.

PanKSEPP, J. B., \& Huber, R. (2004). Ethological analyses of crayfish behavior: A new invertebrate system for measuring the rewarding properties of psychostimulants. Behaviour \& Brain Research, 153, 171-180.

Patullo, B. W., \& Macmillan, D. L. (2006). Corners and bubblewrap: The structure and texture of surfaces influence crayfish exploratory behaviour. Journal of Experimental Biology, 209, 567-575.

Rasnow, B., Assad, C., Hartmann, M. J., \& Bower, J. M. (1997). Applications of multimedia computers and video mixing to neuroethology. Journal of Neuroscience Methods, 76, 83-91.

ReYNOLDS, D. R., \& RiLeY, J. R. (2002). Remote-sensing, telemetric and computer-based technologies for investigating insect movement: A survey of existing and potential techniques. Computers \& Electronics in Agriculture, 35, 271-307.

SAMs-DodD, F. (1995). Automation of the social interaction test by a video-tracking system: Behavioral effects of repeated phencyclidine treatment. Journal of Neuroscience Methods, 59, 157-167.

Schmitz, B., \& Herberholz, J. (1998). Snapping behaviour in intraspecific agonistic encounters in the snapping shrimp (Alpheus heterochaelis). Journal of Bioscience, 23, 623-632.

SCHÜDER, I., PORT, G., \& BENNISON, J. (2004). The behavioural response of slugs and snails to novel molluscicides, irritants and repellents. Pest Management Science, 60, 1171-1177.

Shuranova, Z., Burmistrov, Y., \& Abramson, C. I. (2005). Habituation to a novel environment in the crayfish Procambarus cubensis. Journal of Crustacean Biology, 25, 488-494. 
Sussman, D. (1998). Behavioral measurement in perspective? Trends in Neurosciences, 21, 20-21.

Szentesi, Á., Weber, D. C., \& Jermy, T. (2002). Role of visual stimuli in host and mate location of the Colorado potato beetle. Entomologia Experimentalis et Applicata, 105, 141-152.

Valentinčič, T., Kralj, J., Stenovec, M., Koce, A., \& Caprio, J. (2000). The behavioral detection of binary mixtures of amino acids and their individual components by catfish. Journal of Experimental Biology, 203, 3307-3317.

Wu, B. M., Chan, F. H. Y., Lam, F. K., Poon, P. W. F., \& Poon, A. M. S.
(2000). A novel system for simultaneous monitoring of locomotor and sound activities in animals. Journal of Neuroscience Methods, 101, 69-73.

ZURN, J. B., JiAnG, X., \& MotaI, Y. (2005). Video-based rodent activity measurement using near-infrared illumination. Proceedings of the IEEE Instrumentation and Measurement Technology Conference, $\mathbf{3}$, 1928-1931.

(Manuscript received September 7, 2006; revision accepted for publication February 12, 2007.) 